\title{
Continuous medical education is not only a duty but also a right to claim
}

\author{
Jochen Eulert
}

Received: 30 November 2013 / Accepted: 3 December 2013 / Published online: 24 December 2013

(C) Springer-Verlag Berlin Heidelberg 2013

In almost all countries society demands continuous medical education (CME) and training from the individual doctor, and worldwide it is seen as his essential duty. Many if not all areas of society look for a well-trained and experienced doctor:

- Governments require the best treatment for citizens/voters

- Insurance companies require the best treatment for their clients

- Hospitals/employers require well-trained surgeons to have full beds

- Industry requires doctors who are capable of using their instruments properly

- $\mathrm{CME}$ authorities require continuous education/training

- Re-certification is required for established doctors.

Above all (and he is absolutely right):

- The patient requires safety and wants to be treated by a well-trained surgeon.

But this duty cannot be left to the doctor's discretion alone, considering it as some kind of private activity. Continuous education must not be a one-way road where the doctors undertake learning and teaching by offering their time and financial resources whilst society reaps all the benefits. Society, and in particular the different players in the health care systems, also have some responsibility in this process by setting up acceptable conditions to allow the individual doctor to obtain the education and training he or she needs to treat his or her patients properly under modern conditions.

\section{J. Eulert $(\square)$}

Judenbühlweg 10, 97082 Würzburg, Germany

e-mail: j-eulert.klh@uni-wuerzburg.de

\section{J. Eulert}

SICOT, Rue de la Loi 26, 1000 Brussels, Belgium
Congresses and courses represent an ideal platform to offer the necessary scientific information and educational tools.

The following conditions should therefore be provided by society:

- Ten days' leave per year to attend congresses and courses

- Financial support from the employer

- Financial support (educational grants) from industry through national or international societies (vs. compliance)

- Costs to be allowable against income tax.
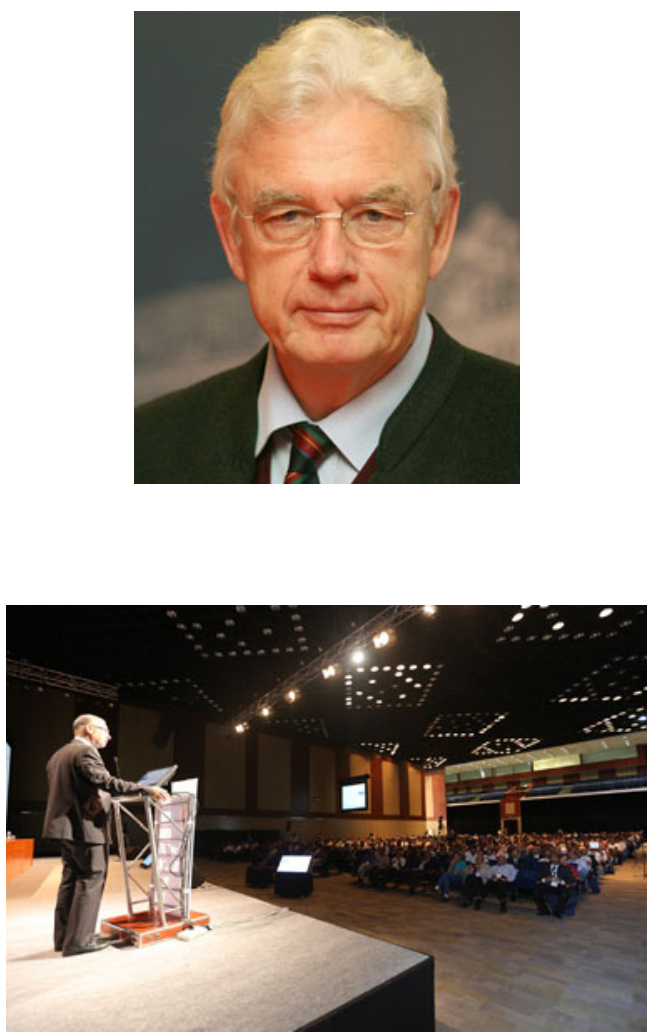

Well attended scientific sesssion SICOT Congress 2013, Hyderabad, India 
Postgraduate education and training is not only a duty but should also be recognised as a right that every doctor should demand to be educated to the level of knowledge and skills needed to provide ideal patient care.
SICOT, together with national and international orthopaedic societies, should start a worldwide campaign to defend this right throughout every corner of the globe. 